\title{
UPDATE OF THE P100-1 CONCRETE PROVISIONS
}

VIOREL POPA - Lecturer, PhD, Technical University of Civil Engineering, Faculty Civil Engineering, e-mail: vpopa@utcb.ro

\begin{abstract}
In an effort to improve the harmonization of the Romanian design codes with the Eurocodes, the revision of the Seismic Design Code, P100-1, started in April 2010 and ended in September 2013. The main issues addressed during the revision process are presented in this paper. They include re-outlining the fundamental requirements for seismic design, revision of the seismic action, improvement of the specific provisions for the design of reinforced concrete, steel, composite, wood and masonry structures and non-structural components. This paper focuses on the specific provisions for reinforced concrete structures but general information about the fundamental requirements and the seismic action are presented as well.
\end{abstract}

Keywords: seismic, code, Eurocode, reinforced, concrete, performance, goals.

\section{Introduction}

In an effort to begin the harmonization of the Romanian seismic design code for buildings with the European standard EN 1998-1 [1], the development of P100-1/2006 [2] started in 2002. That was intended to represent just a step towards its complete harmonization with the European standard. Eventually, the direct enforcement of the Eurocode is desirable. A gradual implementation was necessary due to the wide range of new concepts and methods prescribed by the European standard, in comparison with the previous edition of the Romanian code P100/92 [3]. P100-1/2006 was enforced starting with January 2006.

After 2006, with the support of the Ministry of Regional Development, the Romanian Standards Association translated the relevant Eurocodes and issued its National Annexes. Various Eurocodes, such as EN1992-1-1, EN 1993-1-1 or EN 1994-1-1, were ready to be used in conjunction with P100-1. Moreover, the four years of practical use of P100-1/2006, emphasized some issues that needed to be addressed.

\section{Legal framework}

The revision of P100-1/2006 was requested by the Ministry of Regional Development and Public Administration (MDRAP) and started under the coordination of the Technical University of Civil Engineering of Bucharest in 2010. In September 2013, the new code, denoted P100-1/2013 [4], was published in the Monitorul Oficial of Romania.

P100-1/2013 is a national code enforced by the Romanian government through the MDRAP. The code includes commentaries and examples in its informative annexes. The revision of the code was made by professional engineers and the academic staff of the Technical University of Civil Engineering, "Politehnica" University of Timisoara and "Ion Mincu" University of Architecture and Urbanism. 


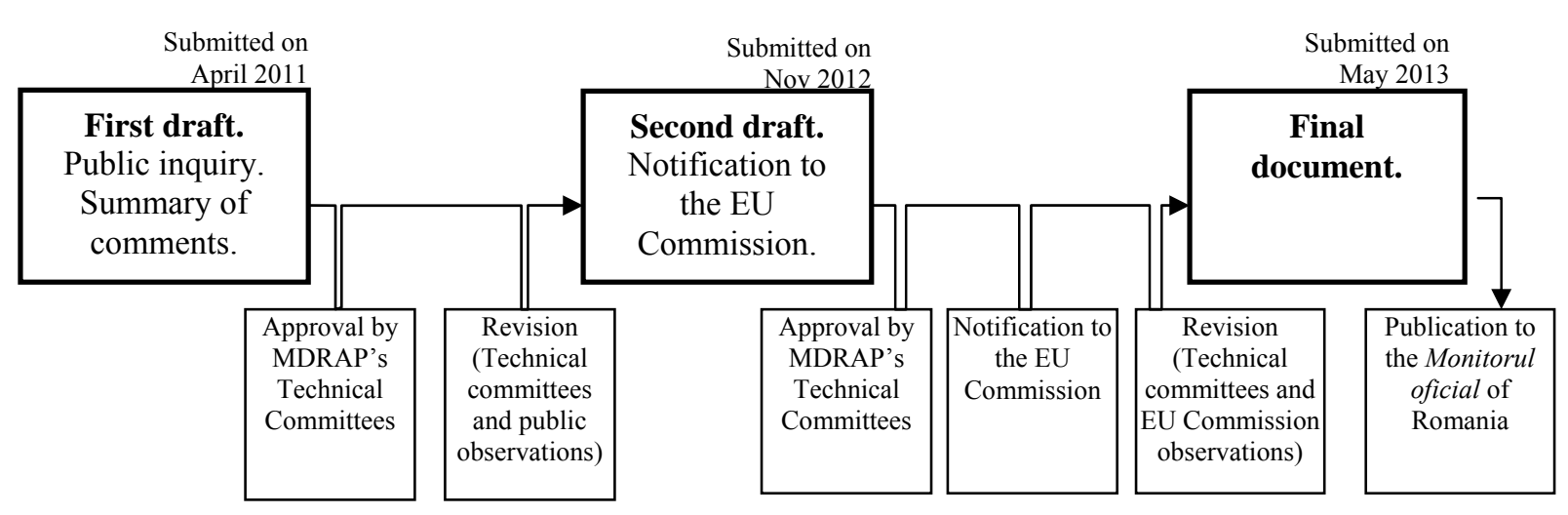

Fig. 1 - Calendar of the revision process

The code provisions are mandatory for all professionals accredited by MDRAP such as structural design checkers or construction experts. While various standards can be used for structural design or assessment in Romania, the final check should be made by accredited professionals that shall apply the national codes enforced by MDRAP.

The Eurocodes are issued in Romania as national standards (SR) by the Romanian Association for Standardization (ASRO). ASRO is a private legal entity of public interest set up as the national standardization body by the Romanian Government. National standards are optional in Romania. A national standard can be enacted only by a central or local public authority in order to protect human health, human life or the environment (Romanian Governmental Ordinance No. 39/1998).

The Romanian Association for Standardization translated and issued the national annexes for most Eurocodes. These are listed as national standards. The national standards listed as reference standards in P100-1 shall be used in structural seismic design according to the provisions of P100-1. The complete list of the reference standards can be found in P100-1 (\$1.5).

P100-1/2013 is enacted for new building design projects contracted after January 2014. For existing buildings, the Seismic Evaluation Code - P100-3/2008 [5] shall be used together with the former version of the Seismic Design Code (P100-1/2006) as it is referenced within the code.

\section{Objectives and basic requirements}

The purpose of the code is to ensure the protection of the residents, the limitation of building damage, the continuous operation of essential facilities and the spill prevention of highly toxic substances in case on an earthquake. Code provisions specify minimum standards for structural safety.

Two fundamental requirements are defined for normal importance buildings in P100-1/2013:

a) Life safety requirement: the structure must withstand the design seismic action without local and global collapse, retaining a residual load bearing capacity after the earthquake. The design seismic action is associated with a mean return interval (MRI) of 225 years (20\% probability of exceedance in 50 years);

b) Damage limitation requirement: the structure must withstand a seismic action having a larger probability of occurrence than the design seismic action, without significant damage, maintaining normal operation. The repairing cost should not be disproportionately high in comparison with the replacement cost of the structure. The corresponding seismic action is associated with a MRI of 40 years (20\% probability of exceedance in 10 years).

Performance levels in P100-1/2013 are in accordance with the provisions of EN1998-1. In comparison with the recommendation of EN 1998-1, the design seismic action in P100-1 has a larger probability of exceedance. EN 1998-1 recommends a design seismic action with 475 years mean return interval (10\% probability of exceedance in 50 years). A design seismic action with 100 years mean return interval was prescribed in P100-1/2006. 


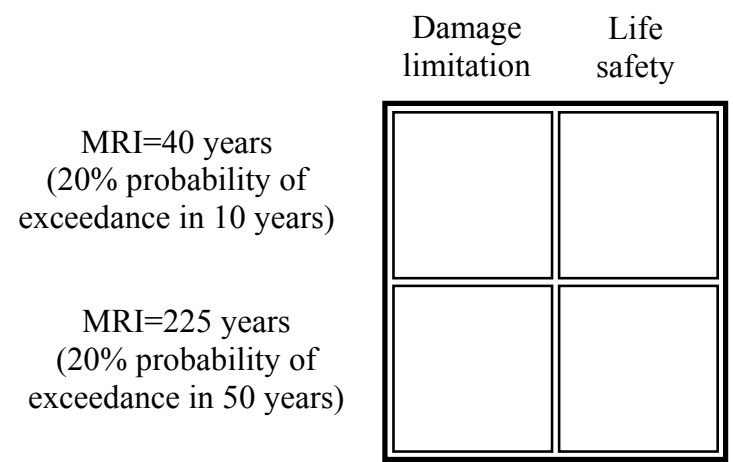

Fig. 2 - Performance objectives for normal importance buildings

For buildings of higher importance, a longer MRI of the design seismic action (associated with a lower probability of exceedance in 50 years) is required. The use of importance factors $\gamma_{\mathrm{I}, \mathrm{e}}$ equal to 1,4 or 1,2 for importance classes I and II, shifts the MRI the design seismic action.

After the 1977 Vrancea earthquake the intensity of the design seismic action was continuously increased. The MRI of the design seismic action prescribed by the seismic design codes changed from $\approx 50$ years in 1992 to 100 years in 2006 and to 225 years in 2013. In the city of Bucharest the design ground acceleration increased from 0,2g in 1992 to $0,3 \mathrm{~g}$ in 2013. A future consideration of the 475 years MRI of the design seismic action, as recommended by EN 1998-1, is foreseeable.

\begin{tabular}{cclc}
$\mathrm{P} 100 / 92$ & $\mathrm{P} 100-1 / 2006$ & $\mathrm{P} 100-1 / 2013$ & $(?)$ \\
\hline 50 Years & 100 Years & 225 Years & 475 Years
\end{tabular}

Fig. 3 - Evolution of the seismic design action

The observance of the fundamental requirements in P100-1 requires checking for two corresponding limit states: Ultimate Limit State (ULS) and Serviceability Limit State (SLS). At the Ultimate Limit State checking of the life safety performance level under a $20 \%$ in 50 -year probability of exceedance, seismic design action is required. At the Serviceability Limit State, the damage limitation performance level under a seismic action having a probability of exceedance of $20 \%$ in 10 years i required to be checked.

\section{Seismic action}

Considering the seismicity of the Romanian territory, seven seismic zones are defined in P100$1 / 2013$ from the point of view of the design peak ground acceleration, $a_{g}$. $a_{g}$ values range from $0,10 \mathrm{~g}$ to $0,40 \mathrm{~g}$ in steps of $0,05 \mathrm{~g}$ (Fig. 4). In comparison with the previous version of the code, roughly a $25 \%$ increase of the design peak ground acceleration can be noticed.

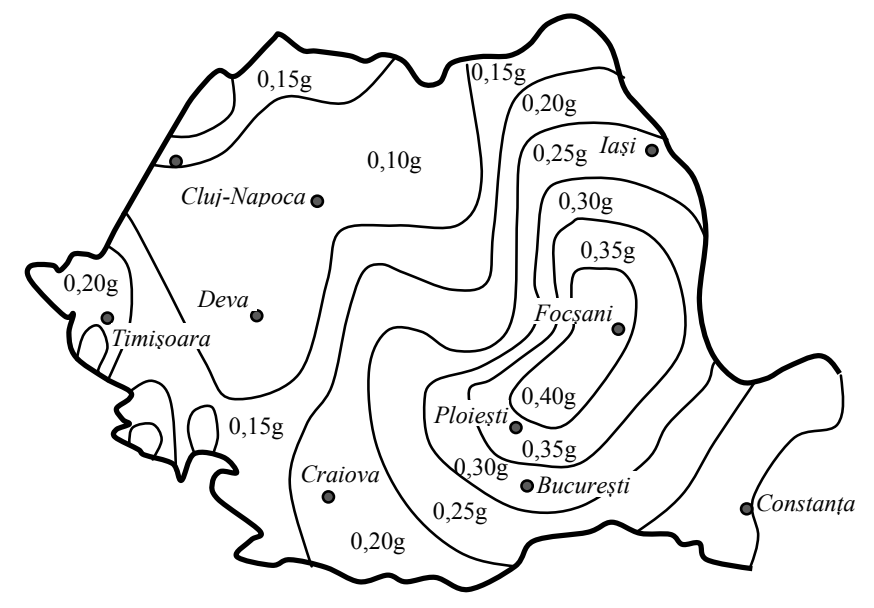

Fig. 4 - Peak design ground acceleration, $a_{g}$ 
As mentioned in P100-1/2013 commentaries, for the areas where de seismic hazard is generated by the Vrancea earthquakes, the catalog of earthquakes from the 20th century was used in the seismic hazard analysis to determine the design peak ground acceleration. Eighty free-field accelerograms recorded in 1977, 1986 and 1990 were considered. The probabilistic analysis of the calculated acceleration response spectra was used to determine the normalized acceleration response spectra $\beta(\mathrm{T})$ as presented in Fig. 5. The equations for calculating the design acceleration spectra are given in Fig. 5 as well.

The impact of the introduction of 225 years MRI design earthquake on the acceleration design spectra, Sd, for reinforced concrete frames and shear walls structures is presented in Fig. 6. In the constant acceleration domain of the response spectrum, increased values with approximately $13,5 \%$ are prescribed by $\mathrm{P} 100-1 / 2013$ in comparison with the 2006 edition. The redefinition of $\mathrm{TB}$ as $0,2 \mathrm{TC}$ results in higher values of the acceleration response spectrum in the $(0, \mathrm{~TB})$ interval. This has a relative importance especially for seismic regions with $\mathrm{TC}=1,6 \mathrm{~s}$ as it is likely to influence the seismic action for buildings having higher vibration modes in this interval. The code newly prescribes a limitation of the acceleration response spectra to $0,2 \mathrm{ag}$ independent of the vibration period. This gives minimum values of $\mathrm{Sd}$ having a practical importance mainly for sites characterized by $\mathrm{TC}=0,7 \mathrm{~s}$. For example, for sites with $\mathrm{TC}=0,7 \mathrm{~s}$ and ag $=0,3 \mathrm{~g}$ (e.g. city of Vaslui) a minimum value of the seismic coefficient of $0,06(\mathrm{Fb}=6 \% \mathrm{~W})$ can be calculated. This minimum value corresponds to buildings with the natural vibration period larger than $1,20 \mathrm{~s}$ for $\mathrm{RC}$ frame structures and 1,70s for shear wall structures.

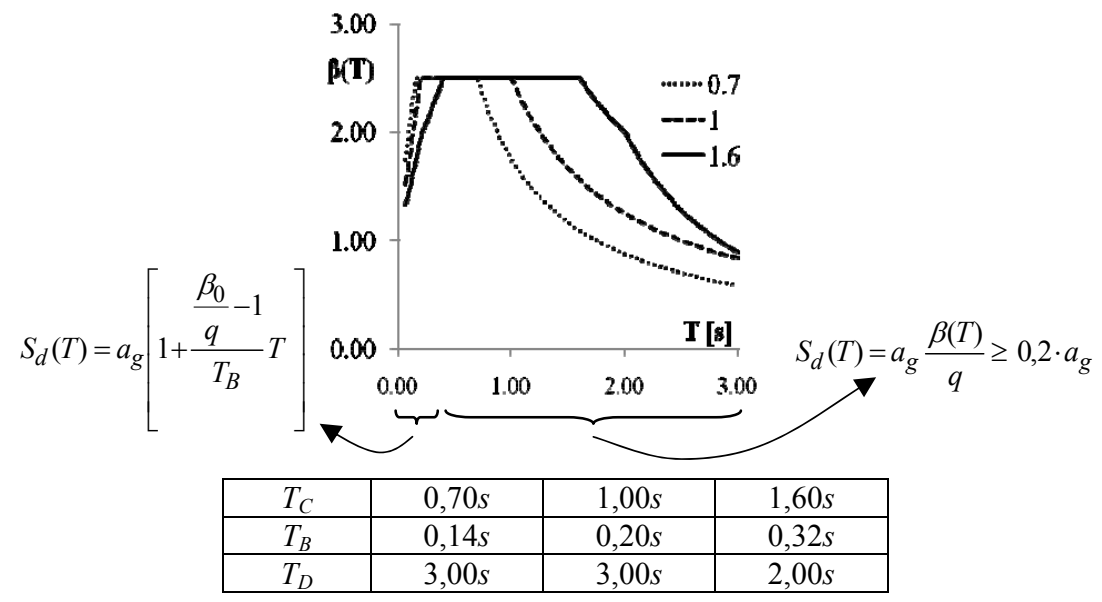

Fig. 5 - Normalized acceleration design spectra

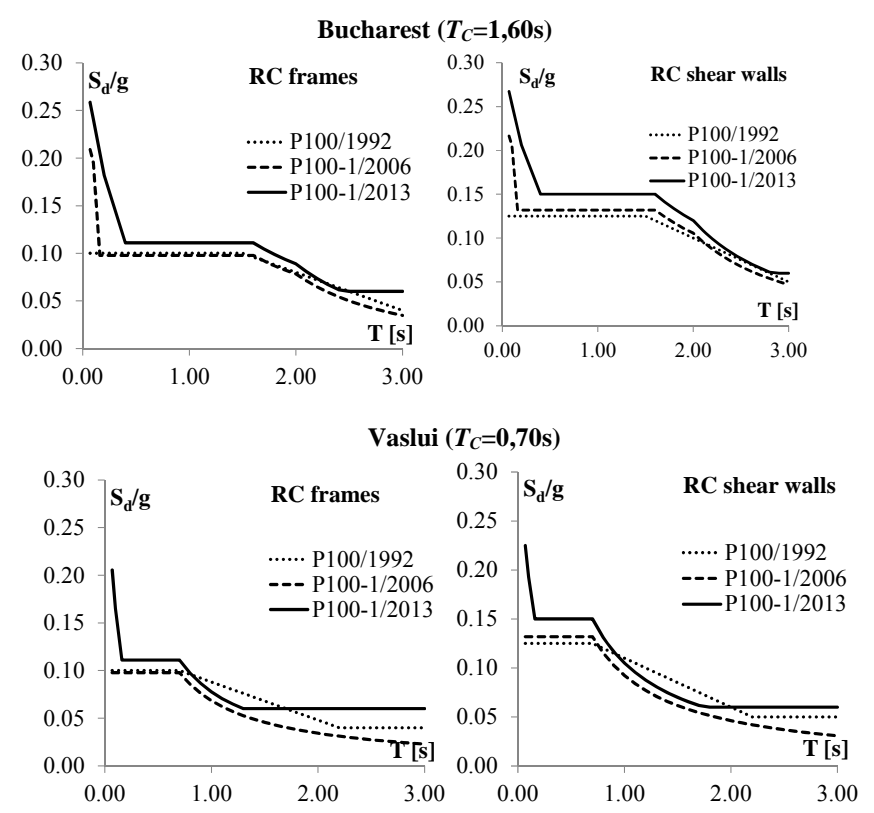

Fig. 6 -Acceleration design spectra for Bucharest and Vaslui (buildings of normal importance) in different codes 


\section{General rules for earthquake resistant design}

The general rules for earthquake resistant design of buildings in P100-1 (§ 4), remain largely the same as in the previous edition.

The re-definition of the importance classes for buildings represents one of the main revisions. Buildings are classified based on the nature of their occupancy and the impact of their failure to the society. The classification in P100-1 is largely the same with the one in the standard "ASCE 7-05 Minimum design loads for buildings and other structures" [6] issued by the American Society of Civil Engineering. In addition to ASCE 7-05, P100-1 includes a classification criterion based on the buildings height. This was explicitly required by MDRAP in order to increase the structural safety of new, relatively high, structures. The classification in EN 1998-1 comprise the same categories, but it was considered not enough detailed to be adopted ,as it is" in P100-1.

P100-1 follows the provisions of the Romanian Basis for Structural Design Code - CR 0/2012 [7], where a unique classification of the buildings for earthquake, snow and wind loads was previously introduced. The importance factors, $\gamma_{\mathrm{I}, \mathrm{e}}$, of 1,40, 1,20, 1,00 and 0,80 corresponding to the importance classes I, II, II and IV are prescribed by P100-1.

\section{Reinforced concrete structures}

\subsection{Reference standards}

SR EN 1992-1-1 [8] is listed in P100-1 as the reference national standard for design of reinforced concrete structures. Therefore, provisions of SR EN 1992-1-1 should be used as required by $\mathrm{P} 100-1$ when an earthquake resistant reinforced concrete structure is designed. The previous version of P100-1 used the former Romanian national standard STAS 10107/0-90 [9] as the reference standard for design of reinforced concrete structures. For the design of earthquake resistant shear wall structures, P100-1/2013 should be used in conjunction with the national code CR2-1-1.1/2013 [10].

\subsection{Ductility classes and behaviour factors}

According to P100-1, the reinforced concrete structures can be designed for three ductility classes: DCH (High ductility), DCM (Medium Ductility) and DCL (Low ductility). For high seismicity regions DCH and DCM are recommended. The design for DCL is allowed only for low seismicity regions with design peak ground accelerations $\mathrm{a}_{\mathrm{g}} \leq 0,1 \mathrm{~g}$. The ductility class DCL has been introduced in this edition to allow the design of earthquake resistant structures with linear response. Essentially, DCL structures can be designed using directly the provisions SR EN 1992-1-1. In this case, the capacity design method does not apply and no special measures to ensure high ductility are necessary. The design procedures for DCM and DCL remain largely the same as in the previous version.

For the ductility class DCL, behaviour factors q equal to 1,5 or 2,0 are prescribed. For moment resisting frame structures, shear wall structures, dual structures and single story frame structures with hinged beams q equals 2,0. For inverted pendulum systems or torsionally flexible systems $q$ equals 1,5 .

The provisions regarding the behaviour factors for short shear walls and single story frame structures with hinged beams for ductility classes DCH and DCM are introduced. Regarding the latter structural type, relatively high values of 3,5 or 3,0 are prescribed under the limitation that the structures have rigid diaphragms at the roof level and the normalized axial compression stress is under 0,25 in all the columns. Otherwise, these structures have to be classified as 
inverted pendulum systems and the corresponding behaviour factor is 2,5 or 2,0. A detailed analysis regarding the behaviour factor for this type of structures, considering the requirements of P100, was performed by Postelnicu \& Damian [11].

Although the difference is not high, P100-1 prescribes behaviour factors systematically larger than EN 1998-1. The behaviour factors of 2,0..6,75 and 1,5..4,75 can be determined for DCH and DCM, respectively.

\subsection{Design forces}

For ductility classes DCH and DCM the capacity design method is recommended. To obtain the hierarchy of resistance one of the following conditions regarding the moments of resistance of beams, $\mathrm{M}_{\mathrm{Rb}}$, and columns, $\mathrm{M}_{\mathrm{Rc}}$, should be satisfied:

(i) at all joints:

$$
\sum M_{R c} \geq \gamma_{R d} \sum M_{R b}
$$

(ii) for each beam

$$
\sum M_{R c} \geq 1,20 \gamma_{R d} \sum M_{R b}
$$

In the case of shear walls structures, to develop a plastic hinge at the bottom of each wall a design bending moment envelope as in Fig. 7 has to be used. The design value of the bending moments outside the plastic region account not only for the moments determined by structural analysis in seismic design situation, $\mathrm{M}_{\mathrm{Ed}}$ ', but also for the bending overstrength of the wall in the plastic hinge region, $\Omega$, and the magnification factor $\mathrm{k}_{\mathrm{M}}=1,3$, used to account for the contribution of the higher vibration modes. In contrast to EN 1998-1, P100-1 design bending moment envelope takes into consideration the wall bending overstrength in the critical region. In common design situations, considering the detailing rules in P100-1 and CR2-1-1.1, the overstrength factors of $1,2 \ldots 2$ are obtained.
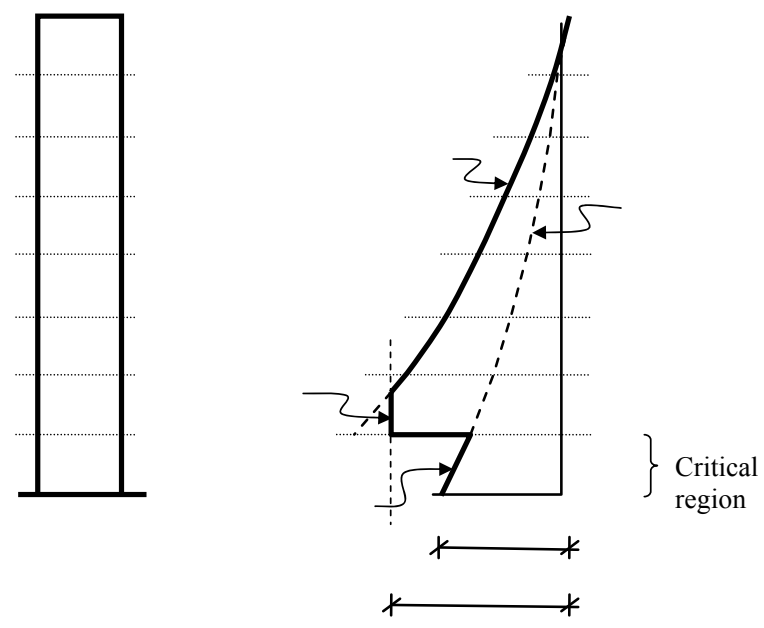

Fig. 7 -Design bending moment envelope for shear walls

The procedures to determine the design shear force for beams and columns in P100-1 and EN 1998-1 are similar.

In case of shear walls, as P100-1 explicitly accounts for the hinge flexural overstrength, the procedures are different. The design shear force, $\mathrm{V}_{\mathrm{Ed}}$, is different from the shear force determined by structural analysis in the seismic design situation, $\mathrm{V}_{\mathrm{Ed}}$, as the amplification caused by the flexural overstrength in the hinge region and the influence of the higher modes are taken into account. The flexural overstrength due to steel strain hardening, $\gamma_{\mathrm{Rd}}$, is multiplied with the overstrength caused by "excessive" longitudinal reinforcement, $\Omega$, to obtain the overall flexural overstrength factor $\Omega \gamma_{\mathrm{Rd}}$. Essentially $\Omega$ can be calculated as the ratio between the design 
value of the bending moment of resistance at the base of the wall, $\mathrm{M}_{\mathrm{Rd}, 0}$, and the corresponding bending moment resulted from structural analysis in the seismic design situation, $\mathrm{M}_{\mathrm{Ed}, 0 .} \mathrm{A}$ similar procedure was prescribed in the previous version of P100-1, but the shape of the design shear force envelope, as presented in Fig. 8, and, the contributions of the higher modes are newly prescribed. In EN 1998-1, for ductility class DCH, the contribution of the higher modes is accounted for by the magnification factor, $\varepsilon$, and a proper design shear force envelope. The design shear force is calculated as $\mathrm{V}_{\mathrm{Ed}}=\varepsilon \mathrm{V}_{\mathrm{Ed}}$. For $\mathrm{DCM}$ the flexural overstrength is not accounted for. ACI 318-11 [12] recommends also the use of capacity-amplified code forces. These forces are obtained by the amplification of the code forces, resulted from the structural analysis, with the flexural overstrength factor. The influence of the higher modes on the shear force distribution is not considered in this standard. Paulay et al. recommends the quantification of the design shear force considering both the flexural overstrength factor and the contribution of the higher modes [13]. SEAOC [14] recommends as well a procedure that accounts for the influence of higher modes.

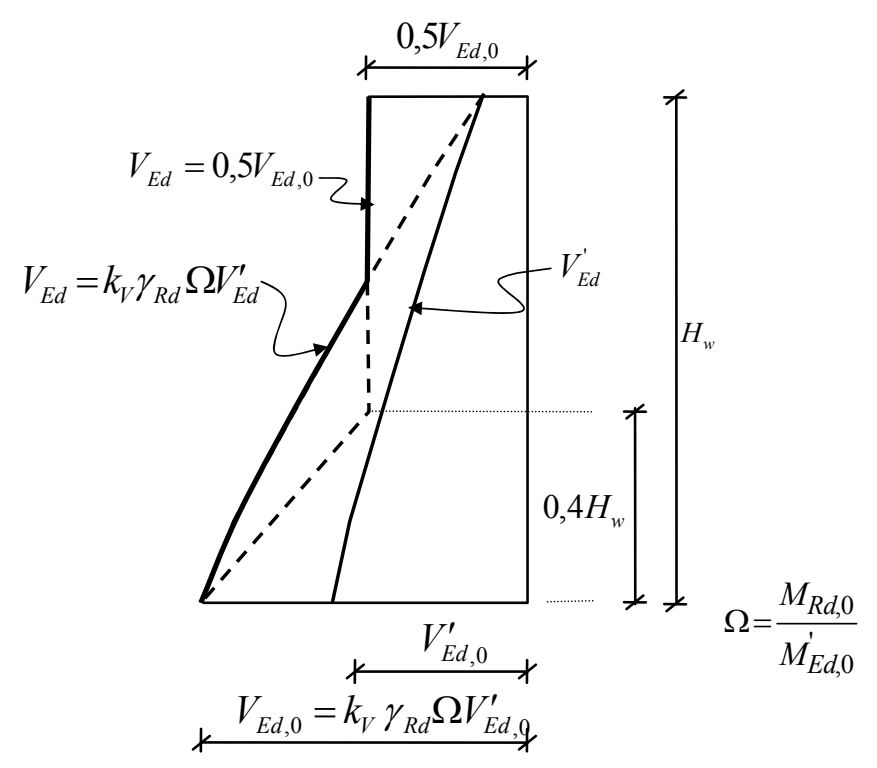

Fig. 8 -Design shear envelope for shear walls

\subsection{Bending and shear capacity}

According to P100-1, the flexural strength of the primary structural elements shall be calculated in accordance with SR EN1992-1-1. Provisions to determine the effective width of the flange for "T" shaped beams and shear walls are given in P100-1.

Shear strength of the primary seismic elements shall be calculated in accordance with SR EN1992-1-1 following the additional provisions in P100-1. The SR EN1992-1-1 provisions for shear strength are based on the plastic truss model. The additional provisions for seismic structures in P100-1 are similar to those in EN1998-1.

Two parameters describe the intensity of the shear action on primary seismic beams. These are the average shear stress, $\mathrm{v}$, and the ratio between the maximum and minimum acting shear forces, $\zeta$. According to the code, if a complete reversal of the shear force at one end of the beam is expected the average shear stress is strictly limited or inclined shear reinforcement is necessary. This is the case when the gravity component of the shear force, $V_{\mathrm{Edb}}$, grav, is small in comparison with the seismic component, $\mathrm{VE}_{\mathrm{db}}$, seism. Full reversal shear forces lead to a rapid deterioration of the concrete element and a poor hysteretic response. 


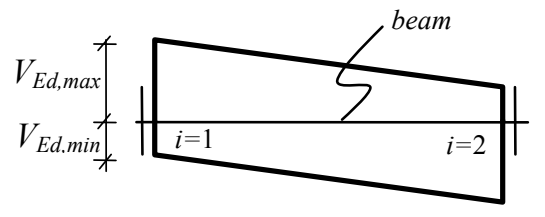

$$
\begin{gathered}
v=\frac{\left|V_{E d}\right|_{\max }}{b d f_{c t d}} \\
\zeta=V_{E d, \text { min }} / V_{E d, \text { max }}
\end{gathered}
$$

a)

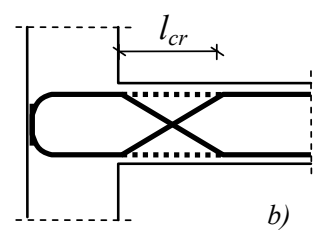

Fig. 9 - Shear envelope (a) and inclined reinforcement in the critical region (b) of beams

If a full reversal of the shear force is not expected, $\zeta>-0,5$, SR EN 1992-1-1 provisions shall be used considering a diagonal strut inclination of $45^{\circ}$. The same procedure applies if $\zeta<-0,5$ given that the average shear stress, $v$, does not exceed $(2+\zeta) f_{\text {ctd }}$, where $f_{\text {ctd }}$ is the design value of the tensile strength of the concrete. If a full reversal of the shear force is expected, $\zeta<-0,5$, and the average shear stress exceeds $(2+\zeta) f_{\text {ctd }}$, inclined shear reinforcement to resist at least half of the maximum shear force, $\left|\mathrm{V}_{\mathrm{Ed}}\right|_{\max }$, should be provided.

For example, in the most aggressive shear action scenario in a critical region of a beam, the maximum and minimum shear forces are equal in magnitude but of opposite signs, $V_{\mathrm{Ed} \text {,max }}=-$ $\mathrm{V}_{\mathrm{Ed} \text {,min, }}$ and $\zeta$ is equal to -1 . In this situation, the average shear stress should not exceed $\mathrm{f}_{\mathrm{ctd}}$, otherwise inclined reinforcement is necessary in the plastic region (Fig. 9, b).

Shear strength of columns shall be calculated according to SR EN 1992-1-1 considering a compression strut inclination angle of $45^{\circ}$.

Shear strength of shear walls shall be calculated in accordance with CR2-1-1.1/2013. The average shear stress in the wall, $\mathrm{v}$, is limited to prevent the diagonal compression failure of the web due to shear. In the critical region of the wall allowable values of $0,15 \mathrm{f}_{\mathrm{cd}}$, for $\mathrm{DCH}$, and $0,18 f_{c d}$, for DCM, are provided, where $f_{c d}$ is the design value of the concrete compressive strength. Outside the critical region the corresponding allowable values can be increased by $20 \%$.

Transversal shear reinforcement should be able to "suspend" the entire design shear force in the critical regions of the wall. The tensile capacity of the acting shear reinforcement, $\Sigma \mathrm{A}_{\text {sh }} f_{y d, h}$, shall be larger than the design shear force, $\mathrm{V}_{\mathrm{Ed}}$. When the amount of acting transversal reinforcement is determined, a $45^{\circ}$ inclination angle of the compression strut shall be considered.

Outside of the plastic region, the contribution of concrete to the shear force capacity can be taken into account. According to CR2-1-1.1, the concrete contribution to the shear strength equals half of the axial force supported by the web of the shear wall.

The CR2-1-1.1 procedure to determine the shear strength of the wall is entirely different from the procedure prescribed by EN1998-1. Several critics were addressed to the procedure in EN 1998-1 [15].
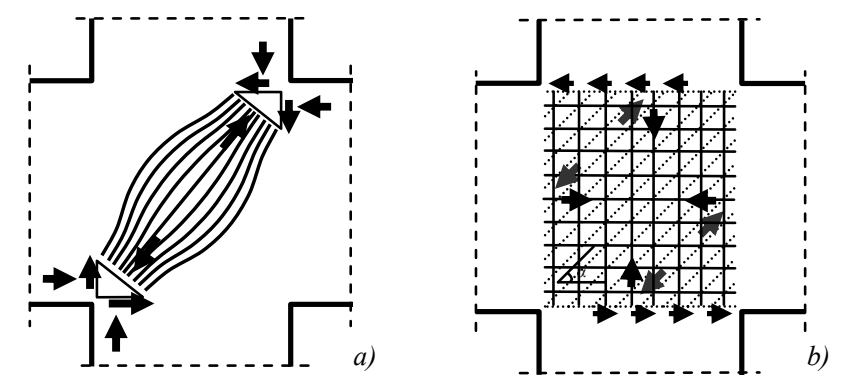

Fig. 10 - Arch (a) and truss (b) load carrying mechanism in beam-column joints

In P100-1/2013, shear strength of beam-column joints is determined based on the arch and truss model developed by Park \& Paulay [16]. To avoid the diagonal compression failure of the joint, the average horizontal shear stress in the joint is limited to $0,3 \mathrm{f}_{\mathrm{cd}}$, for interior joints, and $0,25 \mathrm{f}_{\mathrm{cd}}$, for exterior joints. The horizontal design force in the joint corresponds to the formation of the structural energy dissipation mechanism. To determine the amount of horizontal hoops that 
should be provided in the joint, the truss model is used as well. Members of the elaboration committee of P100-1 give supplementary information about the shear capacity model in [17].

In contrast to P100-1, EN 1998-1 provisions rely on an analytical model to check the shear capacity of the joint against the diagonal compression failure. To determine the amount of horizontal hoops the truss model and the analytical model can be, alternatively, used.

\subsection{Local ductility}

In contrast to EN1998-1, an explicit calculation of the transversal reinforcement amount based on the curvature ductility factor, $\mu_{\varphi}$, is not required by P100-1. Equations prescribed by EN 1998-1 give very large values of $\mu_{\varphi}$ for seismic sites characterized by long control periods, $T_{C}$, as previously reported by Popa \& Postelnicu [18].

According to P100-1, the rotational ductility demand associated with the design earthquake for beams, columns, shear walls and coupling beams should be limited. For a given element, the rotational ductility demand, $\theta_{\mathrm{ULS}}$, can be calculated as the product between the elastic chord rotation resulted from the structural analysis in seismic design situation, $\theta_{\mathrm{e}}$, the behaviour factor, $\mathrm{q}$, and the displacement amplification factor, $\mathrm{c}$. The chord rotation, $\theta_{\mathrm{e}}$, can be calculated based on the deformed shape of the element resulted from the structural analysis as shown in Fig. 11 for a column (a), shear wall (b) and coupled shear wall (c).

Allowable values of the rotation are prescribed by the code. As mentioned in P100-1/2013 commentaries, these values are calibrated considering the Ultimate Limit State fundamental requirement of the design: life safety. Damage in the structural elements is expected under the design earthquake, especially in short and brittle structural elements. The allowable values of the rotation were established based on the results of structural tests performed worldwide.

For example, in case of columns designed and detailed according to the current Romanian practice, minor damage was observed after three loading cycles at $\pm 3 \%$ lateral drift and pushover up to $7 \%$. The specimen presented in Fig. 12 was tested in a structural testing program carried out within the Romanian-Japanese technical cooperation program for seismic risk reduction. Detailed presentation of the results is given by Popa \& Cotofana [19].

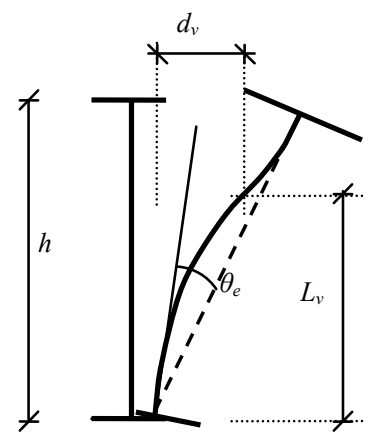

(a)

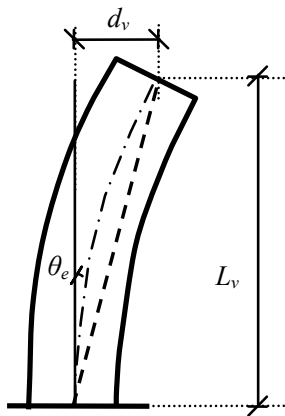

(b)

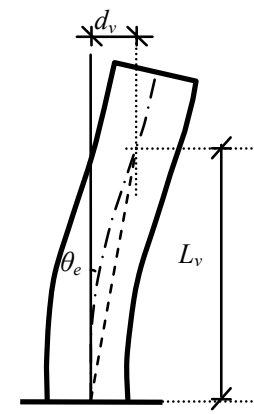

(c)

Fig. 11 - Chord rotation for columns and shear walls

Allowable values of the chord rotation

\begin{tabular}{|c|c|c|}
\hline \multirow{2}{*}{ Element type: } & \multicolumn{2}{|c|}{ Ductility class } \\
\cline { 2 - 3 } & DCH & DCM \\
\hline Long beam: & $3.5 \%$ & $3,0 \%$ \\
\hline Coupling beam & $1,5 \%$ & $1,5 \%$ \\
\hline Coupling beam diagonally reinforced & $4,0 \%$ & $4,0 \%$ \\
\hline Columns & $3,0 \%$ & $2,5 \%$ \\
\hline Shear walls & $2,0 \%$ & $1,5 \%$ \\
\hline
\end{tabular}



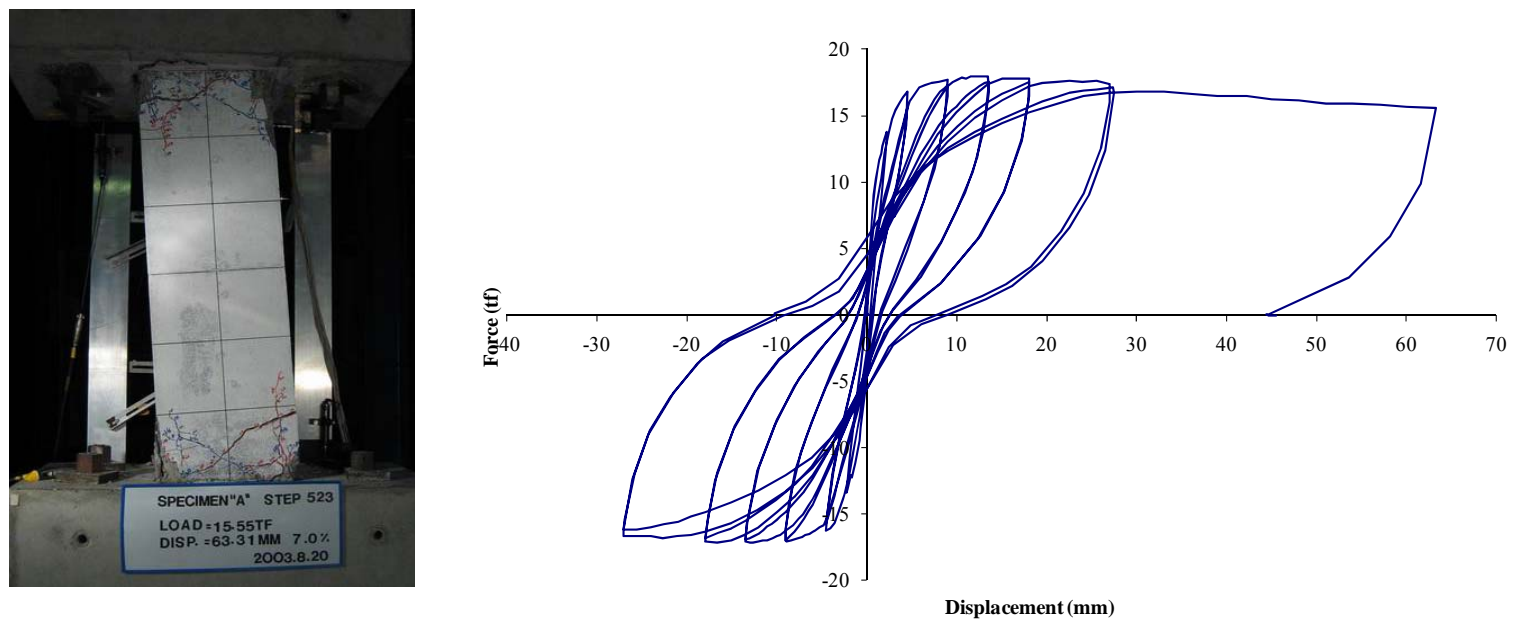

Fig. 12 - Hysteretic behavior of a RC column detailed according to the current practice in Romania

The prescribed allowable values of the rotation can be used only if all code local ductility conditions and detailing measures are followed.

In case of a beam, the limitation of the depth of the compression zone, $x$, to $25 \%$ from the effective depth, $d$, is required. Reinforcement detailing rules are similar to those prescribed by EN 1998-1.

In case of columns the limitation of the normalized axial compression stress, $v_{\mathrm{d}}$, is required. $v_{\mathrm{d}}$ represents the ratio between the maximum axial force in any seismic design situation and the compression resistance of the concrete section, calculated on the basis of the design value of the concrete compressive strength Maximum allowable values of 0,45 for $\mathrm{DCH}$ and 0,50 for DCM are prescribed. $v_{\mathrm{d}}$ can go up to 0,55 in case of DCH and 0,65 in case of DCM but an explicit check of the column ductility is required in this situation and the allowable values of the chord rotation prescribed by the code cannot be used for checking the local ductility.

The normalized axial compression force is a key parameter describing the local ductility of RC columns. If the axial force is reasonably limited, minor damage is expected after the occurrence of the design earthquake. For high axial loads brittle or low ductility failure is expected. If the height of the compression zone, calculated using the design strength of concrete, is roughly 0,45 , than an expected value around 0,3 can be determined if the mean concrete compressive strength is used. This allows for a high rotational ductility of the columns.

Local ductility conditions and detailing rules for shear walls and coupling beams are prescribed by CR2-1-1.1.

\section{Lateral displacement limitation}

P100-1 prescribes limitation conditions of the structural lateral displacement at Serviceability Limit State (SLS) and Ultimate Limit State (ULS). In case of SLS, the objectives of the displacement limitation are to limit the damage of the non-structural elements and preserve the integrity of structural elements. In case of ULS, the objectives of the lateral displacement limitation are: to limit the structural damages, to avoid the general collapse of the building, to avoid falling of non-structural components that can put life of the residents in jeopardy, to limit the second order effects and to avoid pounding between adjacent buildings. The displacement limitation procedures are similar to those prescribed in the previous edition of the code.

The structural lateral drift at each level under the SLS earthquake should be limited to the prescribed allowable values, $\mathrm{d}_{\mathrm{r}, \mathrm{a}}$ SLS , of: $0,005 \mathrm{~h}, 0,008 \mathrm{~h}$ and $0,01 \mathrm{~h}$, where $\mathrm{h}$ is the story clear height. The allowable values depend on the nature of non-structural components and their 
connections with the structural elements. $0,005 \mathrm{~h}$ corresponds to brittle non-structural components, 0,008 to deformable non-structural components and $0,01 \mathrm{~h}$ is prescribed for structures with no non-structural components attached.

The lateral drift under the SLS earthquake can be calculated as the product between the drift resulted from the structural analysis in the seismic design situation, $\mathrm{d}_{\mathrm{re}}$, the behaviour factor, $\mathrm{q}$, and the displacement reduction factor equal to 0,5 that accounts for the lower MRI of the seismic action associated with the damage limitation requirement. This approach is similar to the one in EN 1998-1. In calculation of $\mathrm{d}_{\mathrm{ra}}$, half of the gross moment of inertia of the concrete sections should be considered if the non-structural components do not significantly interact with the structure or full values otherwise.

The lateral drift of the structure under the design earthquake (ULS) is calculated as the product between the drift value determined from the structural analysis in the seismic design situation, $\mathrm{d}_{\mathrm{re}}$, the behaviour factor, $\mathrm{q}$, and the displacement amplification factor, c. The amplification factor accounts for the higher displacement of the inelastic systems in comparison with the equivalent elastic systems for structures with natural vibration periods, $T_{1}$, lower than the control period of the acceleration response spectra, $\mathrm{T}_{\mathrm{C}}$. In this interval, the equal displacement rule is not valid. Factor $\mathrm{c}$ was calibrated through a comprehensive parametrical study on single degree of freedom systems considering site specific synthetic accelerograms and the Takeda hysteretic model. Details on the parametrical study are presented by Zamfirescu et al. [20].

In comparison to the previous edition, in this edition of P100-1, c accounts not only for the natural vibration period of the structure and the control period of the acceleration response spectra, but also for the behaviour factor considered in the design.

The allowable value of the lateral drift for the ULS verification is $2,5 \%$. In the calculation of $d_{r e}$ half of the gross moment of inertia of the concrete sections has to be considered.

The limitation of the lateral displacement both for the design and service earthquake is not usually required by the seismic design codes. ASCE 7-05 requires checking only for the design earthquake, while EN 1998-1 requires only checking for the service earthquake. In case of shallow earthquakes most of the buildings have fundamental vibration periods larger than the control period of the acceleration response spectra, $\mathrm{T}_{\mathrm{c}}$, which is rather short. The equal displacement rule applies and the displacement limitations for the service and design earthquake are more or less equivalent

In case or Romanian territory, intermediate Vrancea earthquakes are characterized by rather long control periods, $T_{c}$, of the acceleration response spectra. Displacement limitations for the service and design earthquakes are not equivalent. A unique generalized conservative approach cannot be defined and checking for both limit states is required.

\section{Conclusions}

P100-1/2013 was issued as an effort to enhance the harmonization of the Romanian Seismic Design Code with the European seismic design standard. As various shortcomings of the EN1998-1 were identified, a direct enforcement of this standard in the current design practice was considered not feasible. Moreover, the wide range of new methods and concepts in EN19981required a gradual implementation in practice. Romanian Standard Association translated all the relevant Eurocodes and issued its National Annexes. The list includes Eurocodes 2, 3 and 4 for the design of reinforced concrete, steel and composite structures. Enacting these national standards to be used in conjunction with P100-1 required a revision of this code.

In the new edition of P100-1, the fundamental requirements and the design seismic action are redefined. 
As regards the design of the reinforced concrete structures the following main revisions were performed:

- Introduction of the low ductility class - DCL - for low seismicity regions;

- Revision of the definition of the bending moment and shear design envelopes for shear wall structures;

- Introduction/revision of the shear strength evaluation provisions for beams, columns, joint and shear walls;

- Introduction of a new local ductility checking procedure;

- Revision of the procedure to determine the lateral displacement under the design earthquake.

P100-1 was enforced starting January 2014 for the seismic design of new buildings.

\section{References}

[1] European Committee for Standardization (2004). Eurocode 8: Design of Structures for Earthquake Resistance. Part 1: General Rules, Seismic Actions and Rules for Buildings. EN1998-1. Brussels.

[2] Ministry of Transport, Constructions and Tourism (2006). Seismic Design Code. Part 1 - Design Provisions for Buildings. P100-1/2006. Bucharest, Romania.

[3] Ministry of Public Works and Land Management (1992). Code for seismic design of civil, cultural, agricultural and industrial facilities. P100/1992. Bucharest, Romania.

[4] Ministry of Regional Development and Public Administration (2013Seismic Design Code. Part 3 - Seismic assessment of existing buildings. P100-3/2008. Bucharest, Romania.

[5 Ministry of Regional Development and Tourism (2008). Seismic Design Code. Part 1 - Design Provisions for Buildings. P100-1/2013). Bucharest.

[6] American Society for Civil Engineers (2005). Minimum Design Loads for Buildings and Other Structures. ASCE 7-05. Reston, Virginia

[7] Ministry of Regional Development and Public Administration (2012). Design code: basis of structural design. CR0/2012. Bucharest, Romania.

[8] Romanian Association for Standardization (2004). Eurocode 2: Design of concrete structures - Part 1-1: General rules and rules for buildings. SR EN1992-1-1. Bucharest, Romania.

[9] Romanian Institute of Standardization (1990). Design and detailing of concrete, reinforced concrete and prestressed structural elements. STAS 10107/0-90. Bucharest, Romania.

[10] Ministry of Regional Development and Public Administration (2013). Design code for concrete shear wall structures. CR21-1.1/2013. Bucharest, Romania.

[11] Postelnicu T., Damian I. (2009). Optimizarea proiectarii structurilor pentru hale parter. National Symposium "Noi reglementari pentru beton (producere, proiectare, executie)": Bucharest, Romania: Conspress Bucureşti.

[12] American Concrete Institute. (2011). Building code requirements for structural concrete. ACI 318-11. Farmington Hills, Michigan, USA.

[13] Paulay T, Priestley M.J.N. (1990). Seismic design of reinforced concrete and masonry buildings. The United States of America: John Willey \& Sons, Inc.

[14] Seismology Committee, Structural Engineers Association of California (2008). "Reinforced concrete structures" Article 9.01.010, SEAOC blue book - Seismic design recommendations. California.

[15] Buzăianu B., Zamfirescu D. (2011). Studiu privind aplicarea normelor europene la calculul structurilor cu pereţi structurali din beton armat. Civil Engineering National Conference. Bucharest: Conspress.

[16] Park R., Paulay T. (1975). Reinforced Concrete Structures. The United States of Americ: John Wiley \& Sons.

[17] Postelnicu T., Popa V. (2009). Proiectarea nodurilor cadrelor de beton armat in codurile de proiectare actuale. AICPS Journal no. 2-3/2009. Bucharest: Marlink.

[18] Postelnicu T., Popa V. (2013). Sper o primă revizuire a codului de proiectare seismică. National Symposium "Noi reglementari pentru beton (producere, proiectare, executie)". Bucharest: Conspress.

[19] Popa V., Cotofana D. (2006). Displacement capacity estimation for RC columns. Comparison between analytical and experimental results. $1^{\text {st }}$ European Conference on Earthquake Engineering and Seismology. Geneva, Switzerland.

[20] Zamfirescu D., Gutunoi A., Damian I. (2011). Studiu asupra relaţiei dintre deplasarea inelastică şi cea elastică pentru cutremure vrâncene. Civil Engineering National Conference. Bucharest: Conspress. 